\title{
Role of OATP4C1 in Renal Handling of Remdesivir and its Nucleoside Analog GS-441524: The First Approved Drug for Patients with COVID-19
}

\author{
Toshihiro Sato ${ }^{1}$, Masamitsu Maekawa ${ }^{1}$, Nariyasu Mano ${ }^{1}$, Takaaki Abe ${ }^{2,3,4}$, Hiroaki Yamaguchi ${ }^{5,6}$ \\ ${ }^{1}$ Department of Pharmaceutical Sciences, Tohoku University Hospital, Sendai, Japan; ${ }^{2}$ Division of Nephrology, \\ Endocrinology, and Vascular Medicine, Tohoku University, Graduate School of Medicine, Sendai, Japan; ${ }^{3}$ Division of \\ Medical Science, Tohoku University, Graduate School of Biomedical Engineering, Sendai, Japan; ${ }^{4}$ Department of \\ Clinical Biology and Hormonal Regulation, Tohoku University, Graduate School of Medicine, Sendai, Japan; \\ ${ }^{5}$ Department of Pharmacy, Yamagata University Hospital, Yamagata, Japan; ${ }^{6}$ Department of Pharmaceutical Science, \\ Faculty of Medicine, Yamagata University, Yamagata, Japan
}

\begin{abstract}
Corresponding authors: Toshihiro Sato, Ph.D., Department of Pharmaceutical Sciences, Tohoku University Hospital; 1-1 Seiryo-machi, Aoba-ku, Sendai, Japan 980-8574; TEL: (+81)-22-717-7541; Fax: (+81)-22-717-7545; email: toshihiro.sato@tohoku.ac.jp; Hiroaki Yamaguchi, Ph.D., Department of Pharmacy, Yamagata University Hospital / Department of Pharmaceutical Science, Faculty of Medicine, Yamagata University, 2-2-2 Iida-Nishi, Yamagata, Japan 990-9585; TEL: (+81)-23-628-5827; Fax: (+81)-23-628-5829; email: hiroaki.yamaguchi@med.id.yamagata-u.ac.jp
\end{abstract}

Received, March 14, 2021; Revised, May 3, 2021; Accepted, May 4, 2021; Published, May 14, 2021

\begin{abstract}
Purpose. Remdesivir and its active metabolite are predominantly eliminated via renal route; however, information regarding renal uptake transporters is limited. In the present study, the interaction of remdesivir and its nucleoside analog GS-441524 with OATP4C1 was evaluated to provide the detailed information about its renal handling. Methods. We used HK-2 cells, a proximal tubular cell line derived from normal kidney, to confirm the transport of remdesivir and GS-441524. To assess the involvement of OATP4C1 in handling remdesivir and GS-441524, the uptake study of remdesivir and GS-441524 was performed by using OATP4C1-overexpressing Madin-Darby canine kidney II (MDCKII) cells. Moreover, we also evaluated the $\mathrm{IC}_{50}$ and $K_{\mathrm{i}}$ value of remdesivir. Results. The time-dependent remdesivir uptake in HK-2 cells was observed. The results of inhibition study using OATs and OCT2 inhibitors and OATP4C1 knockdown suggested the involvement of renal drug transporter OATP4C1. Remdesivir was taken up by OATP4C1/MDCKII cells. OATP4C1-mediated uptake of remdesivir increased linearly up to $10 \mathrm{~min}$ and reached a steady state at $30 \mathrm{~min}$. Remdesivir inhibited OATP4C1-mediated transport in a concentration-dependent manner with the $\mathrm{IC}_{50}$ and apparent $K_{\mathrm{i}}$ values of $42 \pm 7.8 \mu \mathrm{M}$ and $37 \pm 6.9 \mu \mathrm{M}$, respectively. Conclusions. We have provided novel information about renal handling of remdesivir. Furthermore, we evaluated the potential drug interaction via OATP4C1 by calculating the $K_{\mathrm{i}}$ value of remdesivir. OATP4C1 may play a pivotal role in remdesivir therapy for COVID-19, particularly in patients with kidney injury.
\end{abstract}

\section{INTRODUCTION}

Remdesivir, a nucleotide analog that inhibits viral RNA-dependent RNA polymerase (RDRP), for treating adults and children hospitalized with severe coronavirus disease 2019 (COVID-19), was approved in the United States on May 1 and in Japan on May 7, 2020 (Fig. 1A).

Several randomized controlled trials (RCTs) were conducted to investigate the effect of remdesivir on patients with COVID-19 (1-4). Yokoyama et al. reported the efficacy of remdesivir for patients with COVID-19 by conducting a network meta-analysis (5). Since the risk of severe symptoms is markedly high in elderly patients with COVID-19, the safety information of therapeutic drugs is essential in addition to the management of the patients' symptoms. Serious adverse events were reported to occur among $23 \%$ of the patients who were administered remdesivir (6). One of the most common serious adverse events, whose mechanism remains unknown, is acute kidney injury (6). Thus, appropriate administration method, including drug dose and duration, as well as drug safety information, such as side effects, need to be further assessed.

To assess the safety of drugs, a detailed understanding of drug profiles, particularly pharmacokinetics, is necessary. The summary on compassionate use provided by European Medicines Agency (EMA) states that remdesivir 
is a substrate of organic anion transporting polypeptide (OATP) 1B1 and P-glycoprotein (P-gp), which regulate both beneficial and adverse effects of various drugs (7). Moreover, remdesivir interacts with various drug transporters and cytochrome P450s (CYPs) such as CYP3A4, OATP1B3, bile salt export pump (BSEP), multidrug resistance-associated protein (MRP) 4, and $\mathrm{Na}^{+}$-taurocholate cotransporting polypeptide (NTCP) (7).

In contrast, pharmacokinetic data among individuals with normal kidney function demonstrated that remdesivir and its active metabolite are predominantly $(74 \%)$ eliminated via the renal route; however, information regarding renal uptake transporters is limited. In the overexpressing cell system, human organic anion transporters (OAT) 1 and 3 did not transport remdesivir and its major systemic metabolites, GS-704277 and the nucleoside analog GS-441524 (Fig. 1B) (7).
A

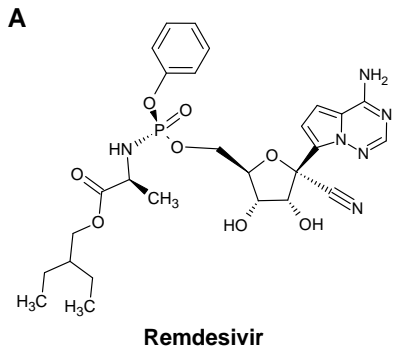

B

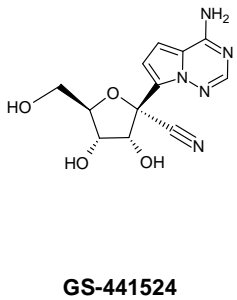

Figure 1. Chemical structures of remdesivir (A) and GS-441524 (B).

OATP4C1 is the only member of OATP family found to be predominantly expressed in the kidney. OATP4C1, which is localized in the basolateral membrane of the proximal tubule, plays a pivotal role in urinary secretion of cardiac glycosides (digoxin and ouabain), thyroid hormones (triiodothyronine $\left[\mathrm{T}_{3}\right]$ and thyroxine), cAMP, methotrexate, sitagliptin, estrone 3-sulfate, chenodeoxycholic acid, and glycocholic acid (8-10). Moreover, our previous study demonstrated that 10 drugs, namely nicardipine, spironolactone, fluvastatin, crizotinib, levofloxacin, clarithromycin, ritonavir, saquinavir, quinidine, and verapamil strongly interacted with OATP4C1 (11).

In the present study, we evaluated the interaction of remdesivir and its nucleoside analog GS-441524 with OATP4C1 to provide the detailed information on renal handling of remdesivir. We assume that the data we provided will contribute to the safety use of remdesivir for patients with COVID-19.
ABBREVIATION. COVID-19: Coronavirus Disease 2019; ESI: Electrospray ionization; HPLC: High performance liquid chromatography; $\mathrm{IC}_{50}$ : Half maximal $(50 \%)$ inhibitory concentration; IS: Internal standard; KH buffer: Krebs-Henseleit buffer; LC/MS/MS: Liquid chromatography/tandem mass spectrometry; OAT: Organic anion transporter; OATP: Organic anion transporting polypeptide; OCT: Organic cation transporter; P-gp: P-glycoprotein; SRM: Selected reaction monitoring; $\mathrm{T}_{3}$ : Triiodothyronine

\section{MATERIALS AND METHODS}

\section{Materials}

Remdesivir (Fig. 1A) and GS-441524 (Fig. 1B) were purchased from Selleck Chemicals (Houston, TX). All other chemicals were commercially available and were of the highest possible purity.

\section{Cell culture}

Human kidney proximal tubule cell line HK-2 (CRL2190) and Canine kidney cell line MDCKII (CRL2936) were purchased from ATCC. OATP4C1/MDCKII and mock cells, which were established in our laboratory, were cultured in Dulbecco's modified Eagle's medium (DMEM) supplemented with $10 \%$ fetal bovine serum (FBS) and G418 $(0.5 \mathrm{mg} / \mathrm{mL})$ according to our previous report (11). HK-2 cells were cultured in DMEM/Ham's F12 supplemented with 10\% FBS and penicillin-streptomycin $(100 \mathrm{U} / \mathrm{mL})$. All cells were cultured under an atmosphere of $5 \% \mathrm{CO}_{2}$ and $95 \%$ air at $37^{\circ} \mathrm{C}$.

\section{Transport studies}

The cellular uptake in monolayer cultures grown on 24-well plates was measured. After the first wash, cells were pre-incubated in Krebs-Henseleit $(\mathrm{KH})$ buffer $(118 \mathrm{mM} \mathrm{NaCl}$, $23.8 \mathrm{mM} \mathrm{NaHCO} 3,4.83 \mathrm{mM} \mathrm{KCl}, 0.96 \mathrm{mM}$ $\mathrm{KH}_{2} \mathrm{PO}_{4}, \quad 1.20 \quad \mathrm{mM} \quad \mathrm{MgSO}_{4}, \quad 12.5 \quad \mathrm{mM}$ $N$-(2-hydroxyethyl)piperazine- $N$ '-2-ethanesulpho nic acid, $5.0 \mathrm{mM}$ D-glucose, and $1.53 \mathrm{mM} \mathrm{CaCl}_{2}$, $\mathrm{pH}$ 7.4). Moreover, the cellular uptake was initiated by adding $\mathrm{T}_{3}$ (with or without any of trial drugs) or remdesivir or GS-441524. At the indicated times, the uptake was terminated by replacing the uptake buffer with ice-cold $\mathrm{KH}$ buffer and then washing twice with ice-cold $\mathrm{KH}$ buffer. Concentration of $\mathrm{T}_{3}$ or remdesivir or GS-441524 was measured via liquid chromatography/tandem mass spectrometry (LC/MS/MS). Furthermore, the cellular uptake was calculated by dividing the uptake amount by the protein count of the cells.

\section{siRNA Transfection}

HK-2 cells were seeded in 24-well cell culture 
plates at a density of $5.0 \times 10^{4}$ cells/well with antibiotics-free DMEM/Ham's F12. Transfection of siRNAs was performed using Lipofectamine ${ }^{\circledR}$ RNAiMAX Reagent (Thermo Fisher Scientific) $24 \mathrm{~h}$ after seeding. SLCO4Cl siRNA (SASI_Hs01_00203727) and negative control (MISSION $^{\circledR}$ siRNA Universal Negative Control \#SIC001) were obtained from Sigma-Aldrich (St. Louis, MO). Each siRNA diluted in Opti-MEM I Reduced Serum medium and Lipofectamine ${ }^{\circledR}$ RNAiMAX Reagent were mixed gently and incubated at room temperature for $5 \mathrm{~min}$. These mixtures were added to each well. The cells were incubated for $48 \mathrm{~h}$ at $37^{\circ} \mathrm{C}$ under $5 \% \mathrm{CO}_{2}$ and then used for experiments.

\section{RT-PCR}

Total RNA was isolated from the cultured cells using TriPure ${ }^{\mathrm{TM}}$ Isolation Reagent (Sigma-Aldrich), and cDNA was prepared from total RNA using ReverTra Ace ${ }^{\circledR}$ qPCR RT Master Mix (TOYOBO, Osaka, Japan) according to the manufacturer's protocol. Quantitative-PCR was performed with KAPA SYBR Fast qPCR Kit (NIPPON Genetics Co., Ltd., Tokyo, Japan) using $20 \mathrm{ng}$ of cDNA. Primer sequences are shown in the supporting information (Supplementary Table 1). Amplification and detection for Quantitative-PCR were carried out on a StepOnePlus real-time PCR system (Applied Biosystems, Foster City, CA). The relative mRNA expression was determined by the $2-{ }^{\Delta \Delta} \mathrm{Ct}$ method. HPRT was used as a housekeeping gene to normalize the relative expression level in samples.

\section{Inhibitory effects of remdesivir}

We calculated $\mathrm{IC}_{50}$ values of remdesivir using a nonlinear least-squares regression analysis of the competition curves using the software KaleidaGraph (Synergy Software Inc., Reading, PA). (Eq. 1). Then, $\mathrm{IC}_{50}$ values were converted to absolute inhibition constant $\left(K_{\mathrm{i}}\right)$ according to previous report (12) (Eq. 2). The following equation was used:

$$
\begin{aligned}
& V=\frac{100 \times I C_{50}{ }^{n}}{I C_{50}{ }^{n}+[1]^{n}} \\
& K_{i}=\frac{I C_{50}}{1+\frac{[S]}{K_{m}}}
\end{aligned}
$$

where $V$ is the transport amount (\% of control), $[I]$ is the inhibitor concentration, $[S]$ is the substrate concentration, $K_{\mathrm{m}}$ is the Michaelis-Menten constant, and $n$ is the Hill coefficient.
Quantification of $T_{3}$, remdesivir, and GS-441524 via LC/MS/MS

Cells were scraped and homogenized in $200 \mu \mathrm{L}$ of water. Thereafter, the cell lysates were deproteinized by adding equal volumes of acetonitrile containing internal standard (IS). The mixture was vortexed and centrifuged at 15,000 $\times$ $g$ for $5 \mathrm{~min}$ at room temperature $\left(20^{\circ} \mathrm{C}\right)$, and the supernatant was used directly for measurement. Chromatographic separation was carried out using a Shimadzu Nexera HPLC System (Shimadzu, Kyoto) with a Cosmosil $5 \mathrm{C}_{18}$-MS-II column (for $\mathrm{T}_{3}$ and remdesivir, $50 \mathrm{~mm} \times 2.0 \mathrm{~mm}$ i.d., $5 \mu \mathrm{m}$, Nacalai Tesque, Inc., Kyoto) or Inertsil $\mathrm{Ph}-3$ column (for GS-441524, $100 \mathrm{~mm} \times 2.1 \mathrm{~mm}$ i.d., $3 \mu \mathrm{m}$, GL Sciences, Inc., Tokyo). To determine $\mathrm{T}_{3}$, remdesivir, and GS-441524 concentrations, the columns were eluted with an isocratic flow of acetonitrile/water/acetic acid (30:70:0.1 $\left(\mathrm{T}_{3}\right)$ or 50:50:0.1 (remdesivir) or 60:40:0.1 (GS-441524), v/v/v, respectively) at a flow rate of $0.2 \mathrm{~mL} / \mathrm{min}$. Thereafter, $5 \mu \mathrm{L}$ of the sample was injected and the column temperature was maintained at $40^{\circ} \mathrm{C}$. Positive and negative ion electrospray tandem mass spectrometric analysis was carried out using an API 5000 tandem mass spectrometer (SCIEX, Framingham, SA) at unit resolution with selected reaction monitoring (SRM). For ESI-, the SRM transitions monitored were $\mathrm{m} / \mathrm{z}, 650>127$ and $\mathrm{m} / \mathrm{z}$ $423>101$ for $\mathrm{T}_{3}$ and pravastatin (IS), respectively. Curtain gas, collision gas, ion spray voltage, turbo gas temperature, nebulizer gas, and turbo gas for ESI- analysis were set at 15 psi, 6 psi, $-4500 \mathrm{~V}, 600^{\circ} \mathrm{C}, 40 \mathrm{psi}$, and $40 \mathrm{psi}$, respectively. For ESI+, the SRM transitions monitored were $\mathrm{m} / \mathrm{z}, 603>200, \mathrm{~m} / \mathrm{z} 292>163$, and $\mathrm{m} / \mathrm{z}, 652>606$ for remdesivir, GS-441524, and $\mathrm{T}_{3}$ (IS), respectively. Curtain gas, collision gas, ion spray voltage, turbo gas temperature, nebulizer gas, and turbo gas for ESI+ analysis were set at $15 \mathrm{psi}, 8$ $\mathrm{psi}, 4500 \mathrm{~V}, 700^{\circ} \mathrm{C}, 70 \mathrm{psi}$, and $70 \mathrm{psi}$, respectively. The other MS/MS parameters in SRM analysis are summarized in Supplementary Table 2. Data were acquired and analyzed using Analyst ${ }^{\circledR}$ software 1.5 (SCIEX).

\section{Statistical analysis}

Data are expressed as mean \pm standard error (S.E.). Multiple statistical comparisons were made by the one-way analysis of variance (ANOVA) followed by Tukey's test. When appropriate, the differences between groups were tested for significance using the unpaired Student's t-test. Statistical significance was indicated by $p$ values less than 0.05 . 


\section{RESULTS}

\section{Remdesivir and GS-441524 uptake by HK-2 cells}

HK-2 cells represent the proximal tubular cell line derived from normal kidney. We used these cells to confirm the accumulation of remdesivir and GS-441524 in renal proximal tubular cells. The results indicated that both remdesivir and GS-441524 uptake reached the steady state at 20 min (Fig. 2A and 2B). At this incubation time point, the uptake of remdesivir and GS-441524 at $37^{\circ} \mathrm{C}$ was 20 and $2.2 \mathrm{pmol} / \mathrm{mg}$ protein, respectively. Corresponding uptake values at $4^{\circ} \mathrm{C}$ were 4.8 and $1.9 \mathrm{pmol} / \mathrm{mg}$ protein for remdesivir and GS-441524, respectively. Remdesivir uptake at $37^{\circ} \mathrm{C}$ was markedly increased comparing to the uptake at $4^{\circ} \mathrm{C}$. Remdesivir uptake by HK-2 cells increased linearly up to $3 \mathrm{~min}$; however, GS-441524 uptake by HK-2 cells did not increase in time-dependent manner.

\section{Search of the responsible transporter for remdesivir uptake}

Based on the results presented in Figure 1, we evaluated the remdesivir uptake by HK-2 using transporter inhibitors for OATs ( $p$-aminohippuric acid (PAH) and probenecid) and OCT2 (ranitidine). The result revealed that the remdesivir uptake by $\mathrm{HK}-2$ cells was not significantly inhibited by OAT and OCT inhibitors (Fig. 3A). In addition, we evaluated the influence of siRNA-mediated silencing of OATP4C1 on remdesivir uptake. The results showed that the uptake of remdesivir decreased by $50 \%$ in HK-2 cells treated with OATP4C1-siRNA (Fig. 3B). OATP4C1 mRNA level significantly decreased to 0.14 -fold under the same condition (Fig. 3C). Thereafter, we also assessed the mRNA expression of organic anion transporters including OATP4C1 in HK-2 cells. The results indicated that only OATP4C1 expression was observed in $\mathrm{HK}-2$ cells in our laboratory (Suppl. Fig. 1). Our HK-2 cells exhibited a time-dependent uptake of $\mathrm{T}_{3}$ (a typical substrate of OATP4C1) (Suppl. Fig. 2). Thus, we decided to perform the remdesivir uptake study using OATP4C1 expressing MDCKII cells.

\section{Time-dependent uptake of remdesivir and GS-441524 by OATP4C1}

We examined the uptake of remdesivir and GS-441524 by OATP4C1 in OATP4C1overexpressing MDCKII cells. Remdesivir was taken up by OATP4C1/MDCKII cells more rapidly than the mock cells (Fig. 4A). OATP4C1-mediated uptake of remdesivir reached a steady state at $30 \mathrm{~min}$ (Fig. 4A). At this incubation time point, the uptake values of remdesivir by mock (vector transfected) cells and OATP4C1/MDCKII cells were 4.3 and 5.1 $\mathrm{pmol} / \mathrm{mg}$ protein, respectively (Fig. 4A), and the OATP4C1-mediated uptake of remdesivir increased linearly up to $10 \mathrm{~min}$ (Fig. 4A); however, OATP4C1-mediated uptake of GS-441524 was not observed (Fig. 4B).
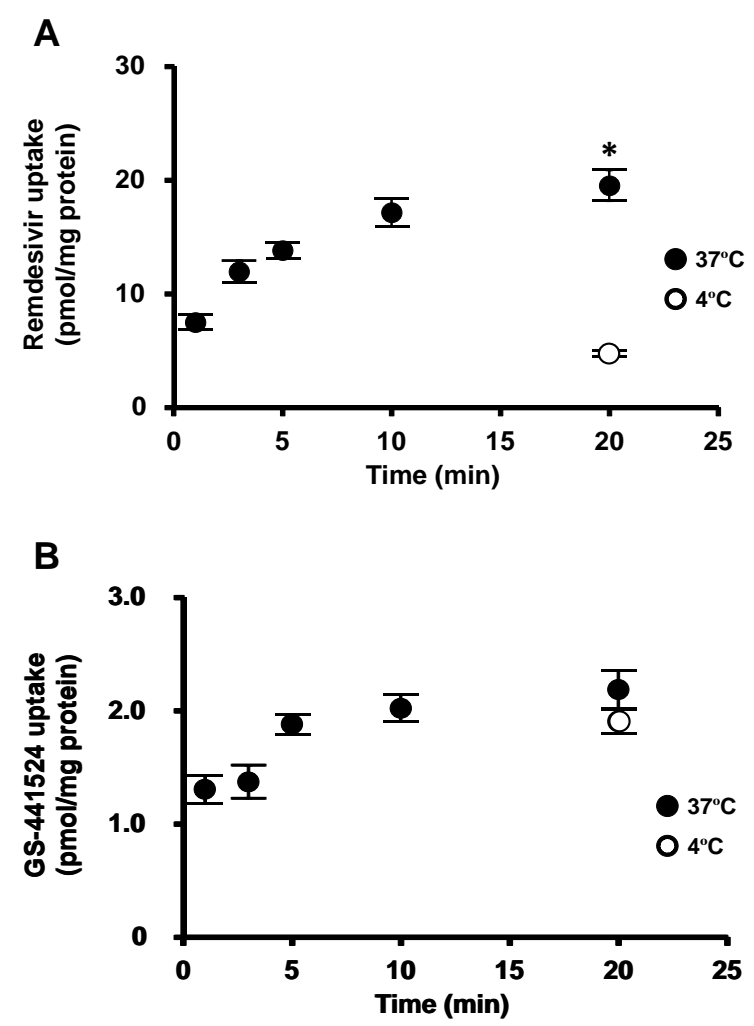

Figure 2. Time-dependent uptake of remdesivir (A) and GS-441524 (B) by HK-2 cells. HK-2 cells were incubated for indicated times at $37^{\circ} \mathrm{C}$ or $4^{\circ} \mathrm{C}$. Closed and open circles represent the uptake at $37^{\circ} \mathrm{C}(\mathbf{O})$ and $4^{\circ} \mathrm{C}(\mathrm{O})$ and, respectively. (A) Remdesivir $(1 \mu \mathrm{M})$, (B) GS-441524 $(1 \mu \mathrm{M})$. Each point represents the mean \pm S.E. $(n=3)$. An asterisk indicates a significant difference from the value at $4^{\circ} \mathrm{C}(\mathrm{p}<0.05)$.

\section{Inhibitory effects of remdesivir and GS-441524 on OATP4C1-mediated transport}

To elucidate the potential drug interactions via OATP4C1, we performed the inhibition study of remdesivir and GS-441524. Herein, the inhibitor concentrations were set much higher than those used in clinics to avoid our overlooking the interaction (evaluated concentrations are 1 200 $\mu \mathrm{M}, 200 \times \mathrm{Cmax}$ (unbound) of remdesivir is $218.4 \mu \mathrm{M}$ based on the Cmax of $5440 \mathrm{ng} / \mathrm{ml}$ (loading dose) and $12 \%$ fraction unbound).

Moreover, the OATP4C1-mediated 
transport was inhibited by remdesivir, but not by GS-441524 (Fig. 5A and 5B). Thereafter, we evaluated the $\mathrm{IC}_{50}$ and apparent $K_{\mathrm{i}}$ values of remdesivir (Eq. 1 and Eq. 2, see Materials and Methods), and observed that remdesivir inhibited OATP4C1-mediated transport in a concentration-dependent manner (Fig. 5A). The $\mathrm{IC}_{50}$ and apparent $K_{\mathrm{i}}$ values of remdesivir were 42 $\pm 7.8 \mu \mathrm{M}$ and $37 \pm 6.9 \mu \mathrm{M}$, respectively.

A

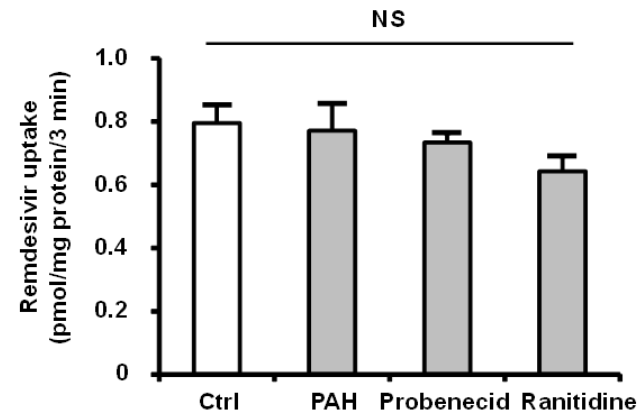

B

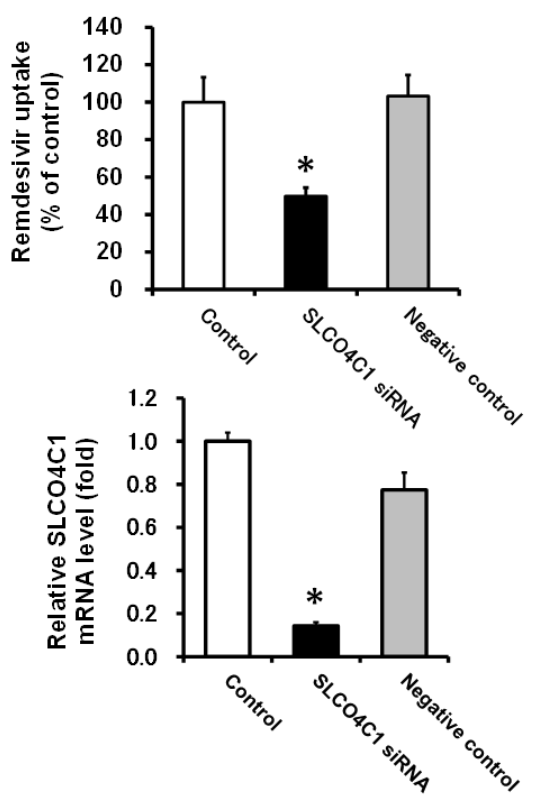

Figure 3. Effects of inhibitors for OAT and OCT on remdesivir uptake by HK-2 cells. (A) HK-2 cells were incubated for $3 \mathrm{~min}$ at $37^{\circ} \mathrm{C}$ with or without the inhibitors $(500 \mu \mathrm{M}$ each): $p$-aminohippuric acid (PAH) (OAT1 inhibitor), probenecid (OAT3 inhibitor), and ranitidine (OCT2 inhibitor). (B) Uptake of remdesivir $(1 \mu \mathrm{M})$ in HK-2 cells treated with OATP4C1- or negative control siRNA was measured. (C) mRNA expression of $\mathrm{SLCO} 4 \mathrm{Cl}$ (OATP4C1) in HK-2 cells treated with OATP4C1-siRNA was evaluated by quantitative-RT-PCR. Each bar represents the mean and S.E. $(\mathrm{n}=3)$. NS indicates no significant difference $(p>0.05)$ and an asterisk indicates a significant difference from the control $(p<0.05)$.

\section{DISCUSSION}

Remdesivir is contraindicated in patients with severe renal impairment; however, presently, no dose modification is recommended in patients with mild and moderate renal impairment. The pharmacokinetics data regarding the elimination and excretion of remdesivir is as follows (the results from Study GS-US-399-4231). Majority of the radioactive dose was recovered from urine (approximately 74\%); the predominant species detected in urine were GS-441524 (49\%), followed by remdesivir (10\%) and other metabolites, accounting for $6 \%$ of total radioactive dose (each less than 2\%). Furthermore, M14 accounted for $12 \%$ of the radioactive dose in feces, and all other metabolites were in trace amounts, accounting for $1 \%$ of total radioactivity (each less than $0.5 \%$ ) (7). Thus, remdesivir and its major metabolites were excreted through urine, and based on the preclinical studies using $\left[{ }^{14} \mathrm{C}\right] \mathrm{remdesivir}(7)$, the detailed understanding of its renal transport was required.
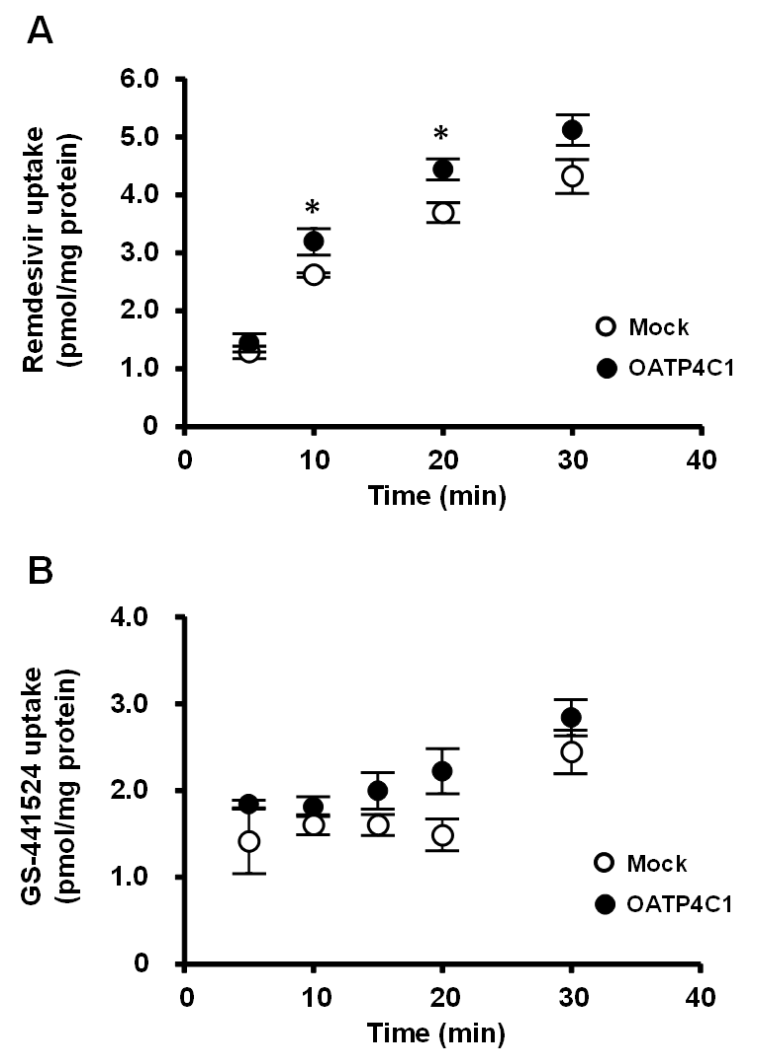

Figure 4. Time-dependent uptake of remdesivir (A) and GS-441524 (B) by mock and OATP4C1 overexpressing MDCKII cells. Cells were incubated for indicated times at $37^{\circ} \mathrm{C}$. (A) Remdesivir (1 $\left.\mu \mathrm{M}\right)$, (B) GS-441524 (1 $\mu \mathrm{M})$. Open and closed circles represent mock cells ( $\bigcirc)$ and OATP4C1 overexpressing MDCKII cells (๑), respectively. Each point represents the mean \pm S.E. $(n=3)$. An asterisk indicates a significant difference from the value of mock cells ( $\mathrm{p}<0.05)$. 
Remdesivir interacts with various drug transporters and cytochrome P450s (CYPs) (7). It is a substrate for OATP1B1 and P-gp (Study AD-399-2007) (7). Moreover, it also inhibits OATP1B1 and OATP1B3 with $\mathrm{IC}_{50}$ values of 2.8 and $2.1 \mu \mathrm{M}$, respectively (Study AD-399-2005) (7) as well as BSEP-, MRP4-, and NTCP-mediated transport, with $\mathrm{IC}_{50}$ values of 22 , 5.1 , and $72 \mu \mathrm{M}$, respectively (7); however, only OAT1 and OAT3 were assessed in the overexpressing cell system among renal uptake transporters, and these transporters did not transport remdesivir and its major systemic metabolites, GS-704277, and the nucleoside analog GS-441524 (Study PC-399-2020; IB Edition 521 February 2020 Section 3.3.6.2) (7).

In our present study, we evaluated the interactions of remdesivir and GS-441524 with renal transporters by using HK-2 and OATP4C1 overexpressing cell lines. From the results, we observed the time- and temperature-dependent remdesivir uptake in HK-2 cells (Fig. 2A); however, time- and temperature-dependent increase in GS-441524 uptake was not observed (Fig. 2B). These results suggested the involvement of transporter molecules in the uptake of remdesivir. Based on the results of inhibition study using OATs and OCTs inhibitors, we speculated the involvement of renal drug transporter OATP4C1 (Fig. 3A). The effect of SLCO4Cl knockdown on remdesivir uptake in HK-2 cells and the expression profile of renal organic anion transporters strongly supported this hypothesis (Fig. 3B, 3C, and Suppl. Fig. 1).

Furthermore, we evaluated the remdesivir and GS-441524 uptake by OATP4C1 using overexpressing system. Our results indicated that remdesivir is the preferred substrate of OATP4C1 compared to GS-441524 (Fig. 4A and 4B). Since remdesivir is a relatively hydrophilic compound, which has both carboxy and hydroxy groups, it theoretically requires a membrane transporter for its renal excretion $(12,13)$; however, the half-life of remdesivir was short in blood and it was quickly converted into the active metabolite in peripheral blood mononuclear cells within 2 hours after administration (13). As aforementioned, the predominant metabolite detected in urine was GS-441524 (49\%), followed by remdesivir (10\%) (7). Further studies are required to elucidate the impact of OATP4C1-medated transport for remdesivir in clinical settings.
A

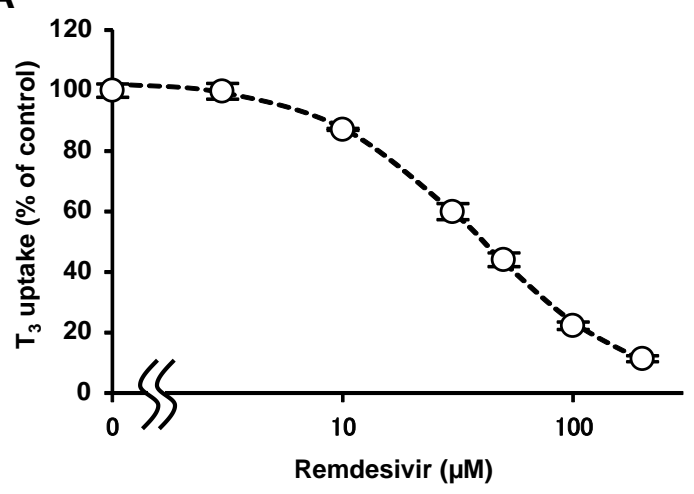

B

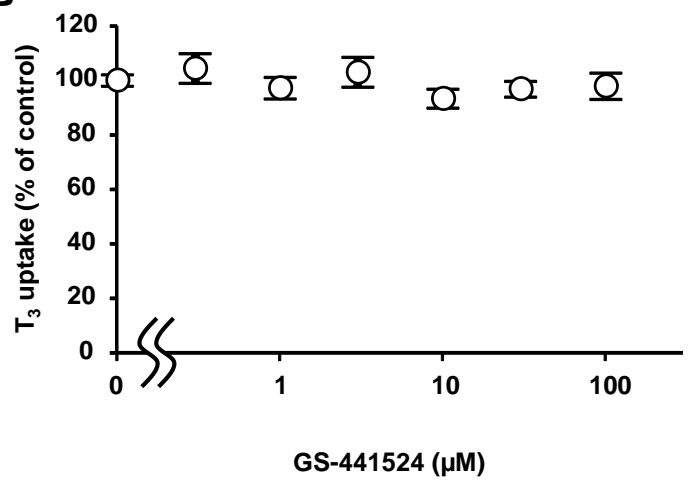

Figure 5. Inhibitory effects of remdesivir (A) and GS-441524 on OATP4C1-mediated uptake. Cells were incubated for 10 minutes at $37^{\circ} \mathrm{C}$ with $1 \mu \mathrm{M} \mathrm{T}_{3}$ in the presence or absence of $(\mathrm{A})$ remdesivir $(1-200 \mu \mathrm{M})$ and (B) GS-441524 (1-200 $\mu \mathrm{M})$. OATP4C1-mediated transport was calculated after by taking the total cellular uptake by OATP4C1-expressing cells and subtracting the nonspecific uptake by mock cells. Each point and bar represent the mean \pm S.E. The data are shown as the percent of transport done by the control. Dotted line are fitted line obtained by a nonlinear leastsquares regression analysis based on Eq. 1 .

In contrast, no information is available about remdesivir use among individuals with eGFR less than $30 \mathrm{ml} / \mathrm{min} / 1.73 \mathrm{~m}^{2}$ (14). Based on the toxicology studies in rhesus monkeys, remdesivir revealed kidney injury with 5 20 $\mathrm{mg} / \mathrm{kg}$ administration, which is higher than the clinical dose (7). Based on the available data from several clinical trials, no significant renal adverse events were reported $(1,15)$; however, severe acute respiratory syndrome coronavirus 2 (SARS-CoV-2) infection leads to acute kidney injury in up to $20 \%-40 \%$ of critically ill patients; herein, the elevation of both remdesivir and its metabolite concentration in plasma should be considered. Previously, our group reported that the expression of renal drug transporters including OATP4C1 were reduced in the model animal with renal failure (16). Since we revealed 
that remdesivir was a substrate of OATP4C1, the elevation of remdesivir concentration in plasma may be a result of OATP4C1 dysfunction in the patients with renal failure.

Furthermore, we performed an inhibition study to provide information on potential drug interaction via OATP4C1 by remdesivir and GS-441524. Our data revealed that remdesivir inhibited OATP4C1-mediated transport in a concentration-dependent manner (Fig. 5A). The apparent $K_{\mathrm{i}}$ value of remdesivir was $37 \pm 6.9 \mu \mathrm{M}$, which is relatively higher than the clinical concentration (4 9 $\mu \mathrm{M}$ as total) (Fig. 5A). Thus, based on these results, remdesivir may not affect the OATP4C1-mediated drug transport in patients with normal kidney function; however, drug interaction via OATP4C1 caused by remdesivir may be observed in patients with renal impairment due to elevated remdesivir accumulation in the body.

\section{CONCLUSIONS}

We have provided the novel information about renal handling of remdesivir. Additionally, we evaluated the potential drug interaction via OATP4C 1 by calculating the $\mathrm{IC}_{50}$ value of remdesivir. OATP4C1 may play a pivotal role in remdesivir therapy for COVID-19, particularly in patients with kidney injury.

ACKNOWLEDGMENTS. This work was supported by Japan Society for the Promotion of Science KAKENHI [Grant Number 18K06742 (Hiroaki Yamaguchi), 20K16037 (Toshihiro Sato)]. We would like to thank Biomedical Research Unit of Tohoku University Hospital (BRU) for technical support. We would like to thank Editage (www.editage.com) for English language editing.

AUTHOR CONTRIBUTIONS. The conception and design of the study, or acquisition of data, or analysis and interpretation of data: Sato and Maekawa. Drafting the article or revising it critically for important intellectual content: Sato, Yamaguchi, and Maekawa. Final approval of the version to be submitted: Sato, Yamaguchi, Maekawa, Abe, and Mano

\section{REFERENCES}

1. Y. Wang, D. Zhang, G. Du, R. Du, J. Zhao, Y. Jin, S. Fu, L. Gao, Z. Cheng, Q. Lu, Y. Hu, G. Luo, K. Wang, Y. Lu, H. Li, S. Wang, S. Ruan, C. Yang, C. Mei, Y. Wang, D. Ding, F. Wu, X.
Tang, X. Ye, Y. Ye, B. Liu, J. Yang, W. Yin, A. Wang, G. Fan, F. Zhou, Z. Liu, X. Gu, J. Xu, L. Shang, Y. Zhang, L. Cao, T. Guo, Y. Wan, H. Qin, Y. Jiang, T. Jaki, F.G. Hayden, P.W. Horby, B. Cao, C. Wang, Remdesivir in adults with severe COVID-19: a randomised, double-blind, placebo-controlled, multicentre trial, Lancet. 395 (2020) 1569-1578. https://doi.org/10.1016/S0140-6736(20)310229.

2. J.H. Beigel, K.M. Tomashek, L.E. Dodd, A.K. Mehta, B.S. Zingman, A.C. Kalil, E. Hohmann, H.Y. Chu, A. Luetkemeyer, S. Kline, D. Lopez de Castilla, R.W. Finberg, K. Dierberg, V. Tapson, L. Hsieh, T.F. Patterson, R. Paredes, D.A. Sweeney, W.R. Short, G. Touloumi, D.C. Lye, N. Ohmagari, M. Oh, G.M. Ruiz-Palacios, T. Benfield, G. Fätkenheuer, M.G. Kortepeter, R.L. Atmar, C.B. Creech, J. Lundgren, A.G. Babiker, S. Pett, J.D. Neaton, T.H. Burgess, T. Bonnett, M. Green, M. Makowski, A. Osinusi, S. Nayak, H.C. Lane, Remdesivir for the Treatment of Covid-19 - Preliminary Report, N. Engl. J. Med. (2020) 1-12. https://doi.org/10.1056/nejmoa2007764.

3. J.D. Goldman, D.C.B. Lye, D.S. Hui, K.M. Marks, R. Bruno, R. Montejano, C.D. Spinner, M. Galli, M-Y. Ahn, R.G. Nahass, Y-S. Chen, D. SenGupta, R.H. Hyland, A.O. Osinusi, H. Cao, C. Blair, X. Wei, A. Gaggar, D.M. Brainard, W.J. Towner, J. Muñoz, K.M. Mullane, F.M. Marty, K.T. Tashima, G. Diaz, A. Subramanian, Remdesivir for 5 or 10 Days in Patients with Severe Covid-19, N. Engl. J. Med. (2020) 1-11. https://doi.org/10.1056/nejmoa2015301.

4. ANON, Gilead announces results from phase 3 trial of investigational antiviral Remdesivir in patients with Severe COVID-19. (June 01, 2020)., Gilead Sci. Inc. (2020).

https://www.gilead.com/news-and-press/press-r oom/press-releases/2020/4/gilead-announces-re sults-from-phase-3-trial-of-investigational-antiv iral-remdesivir-in-patients-with-severe-covid-1 9 (accessed October 9, 2020).

5. Y. Yokoyama, A. Briasoulis, H. Takagi, T. Kuno, Effect of remdesivir on patients with COVID-19: A network meta-analysis of randomized control trials, Virus Res. 288 (2020) 198137.

https://doi.org/10.1016/j.virusres.2020.198137.

6. J. Grein, N. Ohmagari, D. Shin, G. Diaz, E. Asperges, A. Castagna, T. Feldt, G. Green, M.L. Green, F.X. Lescure, E. Nicastri, R. Oda, K. Yo, E. Quiros-Roldan, A. Studemeister, J. Redinski, S. Ahmed, J. Bernett, D. Chelliah, D. Chen, S. 
Chihara, S.H. Cohen, J. Cunningham, A. D’Arminio Monforte, S. Ismail, H. Kato, G. Lapadula, E. L'Her, T. Maeno, S. Majumder, M. Massari, M. Mora-Rillo, Y. Mutoh, D. Nguyen, E. Verweij, A. Zoufaly, A.O. Osinusi, A. DeZure, Y. Zhao, L. Zhong, A. Chokkalingam, E. Elboudwarej, L. Telep, L. Timbs, I. Henne, S. Sellers, H. Cao, S.K. Tan, L. Winterbourne, P. Desai, R. Mera, A. Gaggar, R.P. Myers, D.M. Brainard, R. Childs, T. Flanigan, Compassionate use of remdesivir for patients with severe Covid-19, N. Engl. J. Med. 382 (2020) 2327-2336. https://doi.org/10.1056/NEJMoa2007016.

7. European Medicines Agency, Summary on compassionate use-Remdesivir Gilead, (2020). https://www.ema.europa.eu/en/documents/other /summary-compassionate-use-remdesivir-gilea d_en.pdf (accessed October 9, 2020).

8. T. Mikkaichi, T. Suzuki, T. Onogawa, M. Tanemoto, H. Mizutamari, M. Okada, T. Chaki, S. Masuda, T. Tokui, N. Eto, M. Abe, F. Satoh, M. Unno, T. Hishinuma, K.-I. Inui, S. Ito, J. Goto, T. Abe, Isolation and characterization of a digoxin transporter and its rat homologue expressed in the kidney., Proc. Natl. Acad. Sci. U. S. A. 101 (2004) 3569-3574.

https://doi.org/10.1073/pnas.0304987101.

9. X-Y. Chu, K. Bleasby, J. Yabut, X. Cai, G.H. Chan, M.J. Hafey, S. Xu, A.J. Bergman, M.P. Braun, D.C. Dean, R. Evers, Transport of the dipeptidyl peptidase-4 inhibitor sitagliptin by human organic anion transporter 3 , organic anion transporting polypeptide $4 \mathrm{C} 1$, and multidrug resistance P-glycoprotein., J. Pharmacol. Exp. Ther. 321 (2007) 673-683. https://doi.org/10.1124/jpet.106.116517.contrib ute.

10. H. Yamaguchi, M. Sugie, M. Okada, T. Mikkaichi, T. Toyohara, T. Abe, J. Goto, T. Hishinuma, M. Shimada, N. Mano, Transport of estrone 3-sulfate mediated by organic anion transporter OATP4C1: estrone 3-sulfate binds to the different recognition site for digoxin in OATP4C1., Drug Metab. Pharmacokinet. 25 (2010) 314-317. https://doi.org/10.2133/dmpk.25.314.

11. T. Sato, E. Mishima, N. Mano, T. Abe, H. Yamaguchi, Potential drug interactions mediated by renal organic anion transporter OATP4C1, J. Pharmacol. Exp. Ther. 362 (2017) 271-277. https://doi.org/10.1124/jpet.117.241703.

12. KLR. Brouwer, D. Keppler, KA. Hoffmaster, DAJ. Bow, Y. Cheng, Y. Lai, JE. Palm, B.
Stieger, R. Evers, International Transporter Consortium, In vitro methods to support transporter evaluation in drug discovery and development, Clin. Pharmacol. Ther. 94 (2013) 95-112. https://doi.org/10.1038/clpt.2013.81.

13. S.C.J. Jorgensen, R. Kebriaei, L.D. Dresser, Remdesivir: Review of Pharmacology, Pre-clinical Data, and Emerging Clinical Experience for COVID-19, Pharmacotherapy. 40 (2020) 659-671. https://doi.org/10.1002/phar.2429.

14. S.M. Reza Hashemian, T. Farhadi, A.A. Velayati, A review on remdesivir: A possible promising agent for the treatment of COVID-19, Drug Des. Devel. Ther. 14 (2020) 3215-3222. https://doi.org/10.2147/DDDT.S261154.

15. M.L. Adamsick, R.G. Gandhi, M.R. Bidell, R.H. Elshaboury, R.P. Bhattacharyya, A.Y. Kim, S. Nigwekar, E.P. Rhee, M.E. Sise, Remdesivir in patients with acute or chronic kidney disease and COVID-19, J. Am. Soc. Nephrol. 31 (2020) 1384-1386. https://doi.org/10.1681/ASN.2020050589.

16. S. Mulangu, L.E. Dodd, R.T. Davey, O. Tshiani Mbaya, M. Proschan, D. Mukadi, M. Lusakibanza Manzo, D. Nzolo, A. Tshomba Oloma, A. Ibanda, R. Ali, S. Coulibaly, A.C. Levine, R. Grais, J. Diaz, H.C. Lane, J-J. Muyembe-Tamfum, the PALM Writing Group, A Randomized, Controlled Trial of Ebola Virus Disease Therapeutics, N. Engl. J. Med. 381 (2019)

2293-2303. https://doi.org/10.1056/nejmoa1910993.

17. H. Komazawa, H. Yamaguchi, K. Hidaka, J. Ogura, M. Kobayashi, K. Iseki, Renal Uptake of Substrates for Organic Anion Transporters Oat1 and Oat 3 and Organic Cation Transporters Oct1 and Oct2 is Altered in Rats with Adenine-Induced Chronic Renal Failure, J. Pharm. Sci. 102 (2013) 1086-1094. https://doi.org/10.1002/jps.23433. 
Ssupplementary Table 1. Primer Sequences used for RT-PCR

\begin{tabular}{lccl}
\hline Protein Name & Gene Name & Orientation & \multicolumn{1}{c}{ Sequence } \\
\hline OATP4C1 & SLCO4C1 & Forward & CCGTCACGCAAGGTATTGTA \\
& & Reverse & AATCAGGCCAGTCAGGGAAC \\
OAT1 & SLC22A6 & Forward & ATTGTCCGAACCTCTCTTGC \\
& & Reverse & CGGATCATTGTGGGATACAG \\
OAT3 & SLC22A8 & Forward & CAAACAGGTATGGGCGTAAG \\
& & Reverse & ATAGTCTCTGGCAAGGGCTG \\
HPRT & & Forward & GCGTCGTGATTAGCGATGATGAAC \\
& & Reverse & CCTCCCATCTCCTTCATGACATCT \\
\hline
\end{tabular}

Supplementary Table 2. MS/MS parameters in selected reaction monitoring analysis for simultaneous quantification.

\begin{tabular}{ccccccccc}
\hline No & Compound & Target & $\begin{array}{c}\text { Q1 } \\
(\mathrm{m} / z)\end{array}$ & $\begin{array}{c}\text { Q3 } \\
(\mathrm{m} / z)\end{array}$ & $\begin{array}{c}\text { DP } \\
(\mathrm{V})\end{array}$ & $\begin{array}{c}\text { EP } \\
(\mathrm{V})\end{array}$ & $\begin{array}{c}\text { CE } \\
(\mathrm{V})\end{array}$ & $\begin{array}{c}\text { CXP } \\
(\mathrm{V})\end{array}$ \\
\hline ESI - & & & & & & & & \\
1 & Triiodothyronine & Analyte 1 & 650 & 127 & -140 & -10 & -60 & -20 \\
2 & Pravastatin & IS 1 & 423 & 101 & -100 & -10 & -35 & -15 \\
ESI + & & & & & & & & \\
1 & Remdesivir & Analyte 2 & 603 & 200 & 120 & 10 & 50 & 15 \\
2 & GS-441524 & Analyte 3 & 292 & 163 & 70 & 10 & 32 & 15 \\
3 & Triiodothyronine & IS 2 & 652 & 606 & 40 & 6 & 27 & 16 \\
\hline
\end{tabular}

CE, collision energy; CXP, collision cell exit potential; DP, declustering potential; EP, entrance potential; IS, internal standard 


\section{RT-PCR method}

Total RNA was isolated from the cultured cells using TriPure Isolation Reagent (Sigma-Aldrich) according to the manufacturer's instructions. The concentration and purity of isolated RNA were analyzed with a NanoDrop spectrophotometer (model no. ND-2000, Thermo Fisher Scientific, Waltham, MA). RNA was converted to cDNA using a ReverTra Ace (Toyobo, Osaka, Japan). PCR was performed with Takara Taq Hot Start Version (TaKaRa Biotechnology, Shiga, Japan) using 50 ng of cDNA.

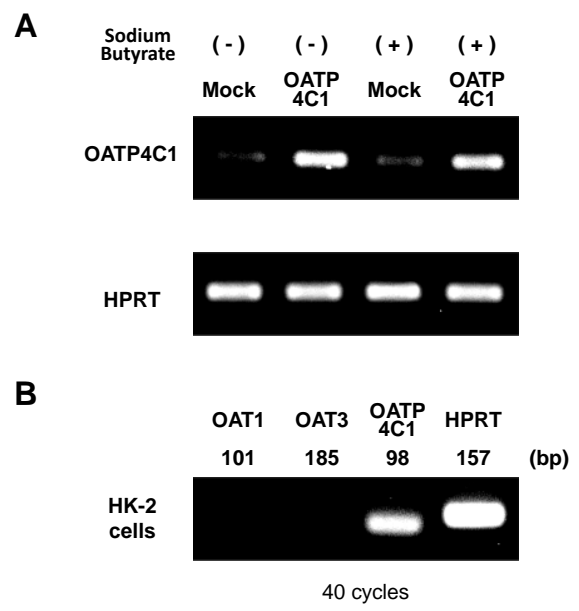

Supplementary Figure 1. Expression of organic anion transporters in mock and OATP4C1-expressing MDCKII cells (A) and HK-2 cells (B). (A) RT-PCR for expression of OATP4C1 mRNA in MDCKII cells with or without 5 mM sodium butyrate. (B) RT-PCR for expression of OAT1, OAT3, and OATP4C1 mRNA in HK-2 cells. The PCR products from both cell lines were run on the same gel to detect OAT1, OAT3, OATP4C1, or HPRT.

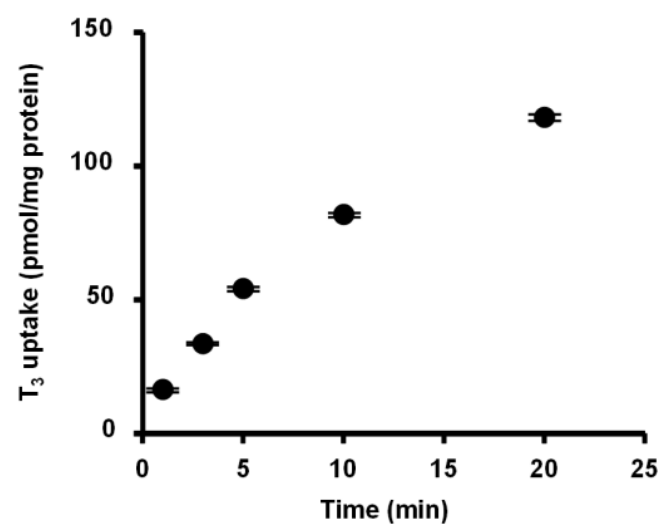

Supplementary Figure 2. Time-dependent uptake of $T_{3}$ by HK-2 cells. HK-2 cells were incubated with $\mathrm{T}_{3}(1 \mu \mathrm{M})$ for indicated times at $37^{\circ} \mathrm{C}$. Each point represents the mean \pm S.E. $(n=3)$. 